\title{
Nonpolar Surface Modification Using Fatty Acids and Its Effect on Calcite from Mineral Carbonation of Desulfurized Gypsum
}

\author{
Chi Wan Jeon, Sangwon Park*, Jun-Hwan Bang, Soochun Chae, Kyungsun Song \\ and Seung-Woo Lee \\ Change Mitigation and Sustainability Division, Korea Institute of Geoscience and Mineral Resources (KIGAM), \\ 124 Gwahang-no, Yuseong-gu, Daejeon 34132, Korea; jcw@kigam.re.kr (C.W.J.); jhbang@kigam.re.kr (J.-H.B.); \\ chae@kigam.re.kr (S.C.); kssong@kigam.re.kr (K.S.); swlee21th@kigam.re.kr (S.-W.L.) \\ * Correspondence: psw1231@kigam.re.kr; Tel.: +82-42-868-3579
}

Received: 28 November 2017; Accepted: 19 January 2018; Published: 22 January 2018

\begin{abstract}
CaCO}_{3}$ is often used as an additive in many industries. However, additional functions are required to expand its applicability. This entails modification of its physicochemical properties. Accordingly, in this study, a particle surface modification treatment was performed on $\mathrm{CaCO}_{3}$ produced from desulfurized gypsum for a range of industrial applications. In the experiment, fatty acids were used to modify the $\mathrm{CaCO}_{3}$ surface, and the scale of the modification effect was based on the degree of change associated with a polar surface taking on nonpolar surface properties. In the preliminary modification experiment, stearic acid was dissolved in 2-propanol or chloroform, and the extent of the reaction and the active ratio were measured according to the stearic acid concentration. The results showed that the effective active ratio, considering the activity to unit adsorption, was higher in 2-propanol than in chloroform. Consequently, the modification solvent used in the experiment changed the $\mathrm{CaCO}_{3}$ surface from a hydrophilic, polarized form to a hydrophobic, nonpolarized form. These results will also allow the $\mathrm{CaCO}_{3}$ produced to be used as a filler in a range of chemical industries.
\end{abstract}

Keywords: calcite; modification; fatty acid; surface control

\section{Introduction}

In many fields such as polymers, paints, thermoplastic resins, and composite materials, a variety of fillers are used for cost-saving and product quality improvement. Among these fillers, the most commonly used is $\mathrm{CaCO}_{3}$, which is generally a white crystalline solid abundant in nature [1]. For a long time, $\mathrm{CaCO}_{3}$ was used primarily as an abrasive or a soil conditioner. Since the early 20th century, it has been used industrially as paint, white pigment, and dye color. In the 1950s, its use as a filler mixed with polymer products increased dramatically in parallel with advances in plastic engineering [2]. More recently, it has been used primarily as a filler or an additive in many industries such as cement, rubber, plastic, building material, and paper [3-5]. $\mathrm{CaCO}_{3}$, as a filler, is used to improve the physical properties of polymer products, improve processability, increase the surface hardness, add functionality, and save costs associated with the volume increase by mixing it with the polymer matrix [6]. $\mathrm{CaCO}_{3}$ is used predominantly in these applications because it is inexpensive and easily applicable, and has adequate specific gravity and a high degree of whiteness as a filler, while having superior physical properties, such as noncombustibility, compared to those of other inorganic materials [7-9].

Increasing the effectiveness of $\mathrm{CaCO}_{3}$ for use in more industries requires added functionality that can satisfy the physicochemical properties to fit that purpose [10]. Until now, methods to add or improve the functionalities of $\mathrm{CaCO}_{3}$ were typically based on controlling its particle size 
or morphology. The $\mathrm{CaCO}_{3}$ filler used in actual industrial applications in Korea mostly consists of heavy $\mathrm{CaCO}_{3}$ obtained from limestone ores with the particle size controlled by pulverizing. In recent times, morphology control using a chemical precipitation reaction and the production of precipitated $\mathrm{CaCO}_{3}$ in ultrafine powder form have also been actively pursued. Atomization of the powder increases the hydrophilic characteristics and diffusion energy on the surface, which can lead to a low dispersion and agglomeration when mixed in an organic polymer matrix [11]. As a result, the usability of $\mathrm{CaCO}_{3}$ as a filler is limited because of its irregular surface and low bonding force. The goal of surface modification of $\mathrm{CaCO}_{3}$ is to address these issues by adding functionalities or modifying the physical properties through changes in the surface properties of the powder to increase its miscibility with a polymer matrix and reduce the surface tension to enhance the physical properties, mechanical performance, thermal resistance, or dispersibility of the powder. Depending on the intended use, the goal of surface modification of $\mathrm{CaCO}_{3}$ includes improved handling, such as enhanced adhesion, agglomeration, fluidity, and dispersibility [12-14]. In addition, combined effects can also be achieved through the addition of optical and surface activation functionality and increased mechanical strength. Such modification effects are often dependent on the types and number of modifiers used. Industrial modifiers that have been primarily used include fatty acids and resin acid, and a wide range of coupling agents, surfactants, amine salts, and esters and polyethylene synthetic compounds are currently in use $[15,16]$.

Recent studies have reported on the use of bio-mineralization. These studies have focused on controlling the physicochemical properties of $\mathrm{CaCO}_{3}$. According to Tester et al., the particle size of amorphous $\mathrm{CaCO}_{3}$ (ACC) can be controlled by using liposomes with phospholipid vesicles [17]. They reported that the use of liposomes enabled good control of ACC nucleation and growth, and could determine the ACC particle size due to its reaction kinetic effect. Research on mesocrystal formation was reported by Yu et al. [18]. In their study, high-magnesium calcite was used to form mesocrystals in aqueous solution. In general, particle size was closely related to reaction time and thereby with crystal growth or formation. Furthermore, phosphatidylcholine showed similar performance with liposomes when $\mathrm{Ca}^{2+}$ ion interaction was considered. According to Yu et al., control of particle size was effected by the difference in energy as the driving force. Tester et al. and Yu et al. used amorphous materials to form $\mathrm{CaCO}_{3}$, which was then coated with liposomes. In these processes, amorphous $\mathrm{CaCO}_{3}$ changed to crystalline phase such as calcite and aragonite. When the driving force decreased, the size of crystals formed was also found to decrease [18].

This study aims to modify the surface of $\mathrm{CaCO}_{3}$ powder. As mentioned, the physicochemical properties of $\mathrm{CaCO}_{3}$ need to be modified to render it suitable for practical application in various industries. Various methodologies and properties were considered in experiments to improve its properties such as dispersibility, hydrophobicity, surface activation, and physical properties including strain, elongation, and tensile strength. This study used a chemical method to dissolve various modifiers such as fatty acids, surfactants, silica, and organosilanes in organic solvents for admixing with $\mathrm{CaCO}_{3}$, in addition to the mechanochemical method of mixing $\mathrm{CaCO}_{3}$ and the modifier on a rotating mill to modify the surface. The aim of these methods was to improve the surface coating effects by increasing the adsorption efficiency under conditions that would eliminate the high level of energy consumption required in conventional dry and wet processes. In the chemical method, considering the solubility and ease of treatment of the modifiers, the adsorption characteristics were derived according to the concentration, reaction speed, and temperature of the modifier in the organic solvent, while the degree of the coating and changes in surface characteristics, surface energy of the powder before and after modification, and physical and chemical characteristics were investigated. Moreover, the increase in the hydrophobic and dispersion effects on the modified powder according to various factors such as the amount of modifier, reaction speed, and reaction temperature were discussed, along with the spectroscopic physicochemical characteristics and functional improvement effects on the products that used the modified powder. 


\section{Materials and Methods}

\subsection{Materials and Reagents}

Thermal power plants operate a desulfurization process using limestone to remove the huge quantities of sulfur produced from coal combustion, and the calcium sulfate produced as a byproduct of this process is referred to as flue gas desulfurization gypsum (FGD-gypsum); most of this is in the form of calcium sulfate dihydrate $\left(\mathrm{CaSO}_{4} \cdot 2 \mathrm{H}_{2} \mathrm{O}\right.$, generally referred to as dihydrous gypsum), which includes moisture determination of two molecules within the structure [19]. For carbon dioxide fixation, this desulfurized gypsum is reacted with ammonia under a flow of carbon dioxide or with ammonium carbonate $\left(\left(\mathrm{NH}_{4}\right)_{2} \mathrm{CO}_{3}\right)$ obtained from the reaction between carbon dioxide and ammonia, producing ammonium sulfate $\left(\left(\mathrm{NH}_{4}\right)_{2} \mathrm{SO}_{4}\right)$ and the calcite forms of $\mathrm{CaCO}_{3}$ as the main products [20]. The $\mathrm{CaCO}_{3}$ used in this study was in calcite form obtained from a gypsum carbonation plant established and operated by the Korea Institute of Geoscience and Mineral Resources (KIGAM, Daejeon, Korea) (Figure 1). The $\mathrm{CaCO}_{3}$ was used without a separate grading process because it comprised fine particles with a uniform particle size distribution [21]. The $\mathrm{CaCO}_{3}$ samples obtained from the plant process were divided into samples that were unprocessed and atomized through a pulverization process, then naturally dried at room temperature or heat treated in an oven at $50-400{ }^{\circ} \mathrm{C}$.

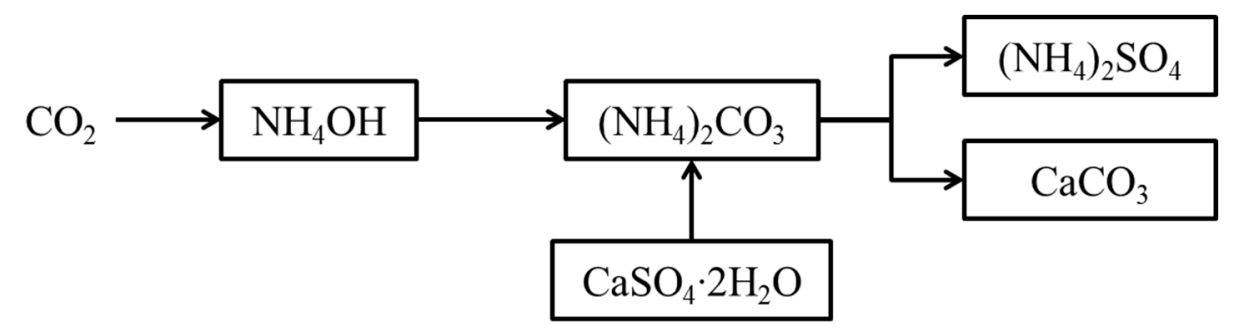

Figure 1. $\mathrm{CaCO}_{3}$ products process with flue gas desulfurization (FGD)-gypsum obtained from the Korea Institute of Geoscience and Mineral Resources (KIGAM) pilot plant.

\subsection{Experimental Methods}

\subsection{1. $\mathrm{CaCO}_{3}$ Surface Modification Using Fatty Acids}

All the fatty acids and organic solvents such as chloroform, acetone, ethanol, and isopropyl used in the experiment were of analytical grade obtained from commercial suppliers and were used as received, while the water used was deionized distilled water.

The fatty acids used as fatty acid modifiers were stearic acid (octadecanoic acid, $\mathrm{C}_{18} \mathrm{H}_{36} \mathrm{O}$ ), palmitic acid (hexadecanoic acid, $\mathrm{C}_{16} \mathrm{H}_{32} \mathrm{O}_{2}$ ), myristic acid (tetradecanoic acid, $\mathrm{C}_{14} \mathrm{H}_{28} \mathrm{O}_{2}$ ), lauric acid (dodecanoic acid, $\mathrm{C}_{12} \mathrm{H}_{24} \mathrm{O}_{2}$ ), and oleic acid (cis-9-octadecenoic acid, $\mathrm{C}_{18} \mathrm{H}_{34} \mathrm{O}_{2}$ ) [15]. The fatty acids were dissolved in an organic solvent and their solubility at room temperature was determined. Stearic acid, palmitic acid, and lauric acid, which are saturated fatty acids, dissolved well in chloroform, whereas they were only slightly soluble in isopropyl alcohol. Moreover, these fatty acids were almost insoluble in methanol, hexane, acetone, and water; therefore, they were excluded. Solutions with the maximum concentration were prepared by dissolving the modifiers at $80 \%$ of the saturation concentration in the corresponding solvent, which were derived experimentally. These solutions were diluted stepwise for use at the desired concentrations and the reaction time was controlled at each concentration to compare the results.

The coating process for the modification of $\mathrm{CaCO}_{3}$ powder was performed in the following manner. A set amount of modifier solution was placed in a three-neck flask with a capacity 2-3 times the volume of solution, to which $\mathrm{CaCO}_{3}$ with capacity to volume ratio of $10 \%-100 \%$ was added. To prevent excessive pressure in the reaction vessel from volatile organic solvents, a condenser column was attached to the upper part of an open triangular flask and maintained with 
a flow of cooling water. The vaporized organic solvent condensed in the condenser and returned to the reaction vessel. The reaction solution was separated into liquid and solid by filtration or centrifugation. The concentration of the liquid solution was determined and the difference versus the initial concentration was calculated to determine the decrease in the amount of the modifier lost through coating the $\mathrm{CaCO}_{3}$ powder. The solids were obtained by filtering the mixture of surface-coated $\mathrm{CaCO}_{3}$ and unmodified $\mathrm{CaCO}_{3}$. The solids were dried at room temperature and underwent a light grinding process or were filtered through a strainer, after which they were used as the test samples to evaluate the modification efficiency or surface characteristics of the modified powder.

\subsubsection{Active Ratio and Dispersion Ratio Measurements}

The change in the surface characteristics of $\mathrm{CaCO}_{3}$ from polar to nonpolar as a result of surface modification was determined by measuring the increase in hydrophobicity. The active ratio was derived by measuring the amount of suspended $\mathrm{CaCO}_{3}$ according to the mutually exclusive polar-nonpolar attraction when modified $\mathrm{CaCO}_{3}$ was added to deionized water. $\mathrm{A} 10 \mathrm{~mL}$ vial was filled in advance with $5 \mathrm{~mL}$ of distilled water, to which $1 \mathrm{~g}$ of modified $\mathrm{CaCO}_{3}$ powder sample was added. The solution was mixed by shaking vigorously for $3 \mathrm{~min}$ with the stopper on, which was repeated twice, and then left to stand for $12 \mathrm{~h}$. Thereafter, when the settled powder, water, and suspended powder layers were separated completely from each other, the settled and suspended layers were acquired separately. After drying the layers, accurate weight measurements were taken. The active ratio was derived using the following equation:

$$
A(\%)=\frac{M_{\mathrm{f}}}{M_{\mathrm{f}}+M_{\mathrm{s}}} \times 100
$$

where $A$ (\%) denotes the active ratio; $M_{\mathrm{f}}$ denotes the weight of $\mathrm{CaCO}_{3}$ from the upper suspended layer (g); and $M_{\mathrm{S}}$ denotes the weight of $\mathrm{CaCO}_{3}$ from the lower sediment layer $(\mathrm{g})$.

A larger active ratio indicates greater hydrophobicity and an excellent modification effect [7]. As a method for evaluating the hydrophobicity or dispersibility of the modified $\mathrm{CaCO}_{3}$ mixed with a nonpolar polymer matrix, the dispersing ratio was calculated by measuring the amount dispersed when the modified and unmodified $\mathrm{CaCO}_{3}$ powders were added to a nonpolar kerosene solvent. The following equation was derived from the volume that appeared when $5 \mathrm{~mL}$ of kerosene and $5 \mathrm{~g}$ of powder were added to a $10 \mathrm{~mL}$ measuring cylinder, and the volume of pure kerosene solvent when this solution was fixed and stabilized for $5 \mathrm{~min}$.

$$
D(\%)=\frac{H_{0}-H}{H_{0}} \times 100
$$

where $D(\%)$ denotes the dispersing ratio; $H_{0}$ denotes the total volume of kerosene solution with powder added $(\mathrm{mL})$; and $H$ denotes the total volume accounted for by the stabilized pure kerosene solvent $(\mathrm{mL})$.

The higher active ratio that displays the exclusivity with highly polar water and dispersing ratio that displays affinity with nonpolar oil showed greater hydrophobicity and improved modification effects.

\subsubsection{Contact Angle Measurement}

When a traditional liquid contact angle measurement method is used, the surface energy of flat surfaces can be obtained easily [22]. This method involves compressing the powder to a disc form and measuring the contact angle of a liquid drop on the surface of the solid. The two-liquid technique is ideal when the surface energy of the solid is large [23]. However, there are difficulties in applying this method to agglomerated $\mathrm{CaCO}_{3}$ powder. Therefore, only the qualitative evaluation results on the major surface change characteristics of modified $\mathrm{CaCO}_{3}$ are presented in this paper. The disc was made using a traditional infrared die fabrication method under controlled conditions with $200 \mathrm{mg}$ 
$\mathrm{CaCO}_{3}$, and the contact angle was measured using a goniometer telescope by placing a drop of liquid onto the sample.

\section{Results and Discussion}

As mentioned, the $\mathrm{CaCO}_{3}$ used in the experiment was obtained from a pilot plant by KIGAM (Korea Institute of Geoscience and Mineral Resources, Daejeon, Korea). With respect to the particle size distribution, $90 \%$ of the unprocessed $\mathrm{CaCO}_{3}$ obtained from the plant process showed a particle size distribution of $<30 \mu \mathrm{m}$, while $50 \%$ showed a particle size $<12.58 \mu \mathrm{m}$ (Figure 2). In addition, $90 \%$ of the $\mathrm{CaCO}_{3}$ atomized through the pulverization process showed a particle size distribution of $<7.65 \mu \mathrm{m}$, while $50 \%$ showed a particle size of $<7.2 \mu \mathrm{m}$. Generally, the particle size of the precipitate $\mathrm{CaCO}_{3}$ (PCC) was smaller than that of the ground $\mathrm{CaCO}_{3}$ (GCC). PCC, for its chemical formation, generally uses soluble precursors, and thus has a small particle size; however, GCC was obtained from limestone, in limestone mining, for example. Therefore, the PCC particle size was mostly uniform in contrast to the GCC particle size. As mentioned in the experimental section, we used PCC for the pilot plant. As a result, its distribution was not different. Additionally, the $\mathrm{CaCO}_{3}$ we used had no relationship with the flotation effect because its distribution was uniform. In other words, we assumed that the main effect of flotation was the degree of surface coverage. Therefore, the $\mathrm{CaCO}_{3}$ used did not have a classification because we considered the practicability. Moreover, the specific surface area was analyzed to check the effect of using fatty acids. This estimation was calculated using the Mastersize 2000 model (Malvern Co. Ltd., Malvern, AR, USA). Additionally, its definition is the total surface area divided by the total volume. The specific surface areas of the untreated and pulverization-treated $\mathrm{CaCO}_{3}$ were $1.02 \mathrm{~m}^{2} / \mathrm{g}$ and $1.62 \mathrm{~m}^{2} / \mathrm{g}$, respectively [24]. Most of the crystalline structures of the $\mathrm{CaCO}_{3}$ samples determined by $\mathrm{X}$-ray diffraction were in the calcite form, while trace amounts of the vaterite form were observed. The purity of $\mathrm{CaCO}_{3}$ was determined by thermogravimetric analysis, by converting the amount decreased by decomposition at high temperatures to the amount of carbon dioxide present in $\mathrm{CaCO}_{3}$ and by determining the unreacted sulfur content; this showed similar results: $94 \%$ and $96 \%$, respectively [24]. Although the $\mathrm{CaCO}_{3}$ that we used had been pretreated by heat, it did not change into $\mathrm{CaO}$ powder. In general, $\mathrm{CaCO}_{3}$ decomposes at high temperatures over $850{ }^{\circ} \mathrm{C}$. However, our study did not use high temperatures. Our previous study also mentioned that this is calcite [24]. The solvent was used only to dissolve the modifier. In this process, only fatty acids were used and, thus, reformation could not be obtained.

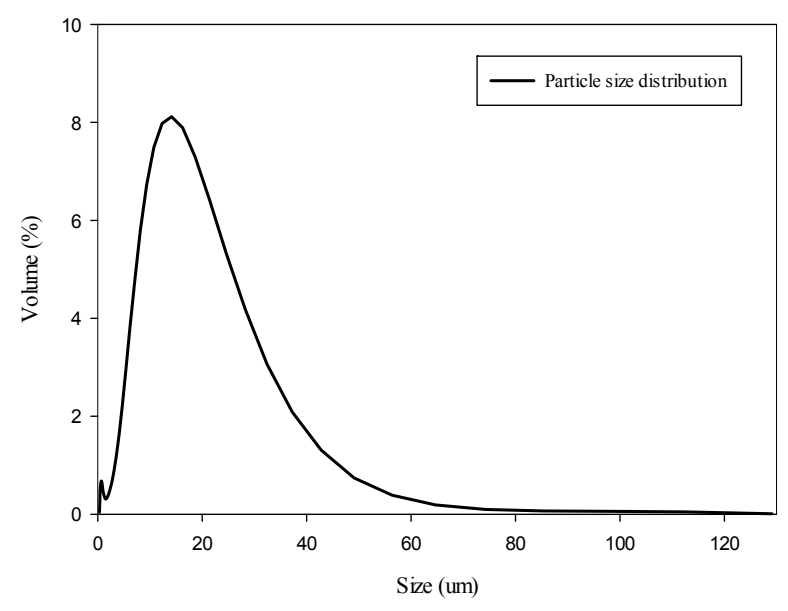

Figure 2. Particle size distribution of ground $\mathrm{CaCO}_{3}$ powder.

\subsection{Pretreatment Activation Effect of $\mathrm{CaCO}_{3}$ Powder}

When a powder is treated at high temperatures, the adsorption area becomes activated, resulting in an increase in the specific surface area [25]. To investigate this effect, the changes in the specific 
surface area were determined according to the temperature of the $\mathrm{CaCO}_{3}$ powder samples that underwent a pulverization treatment compared with the untreated samples [24]. Through the specific surface area analysis, we could guess the effect of modification caused by the fatty acid. Figure 3 shows the relative ratio of the specific surface area of the pulverized (increased in temperature) $\mathrm{CaCO}_{3}$ sample to that of the untreated sample.

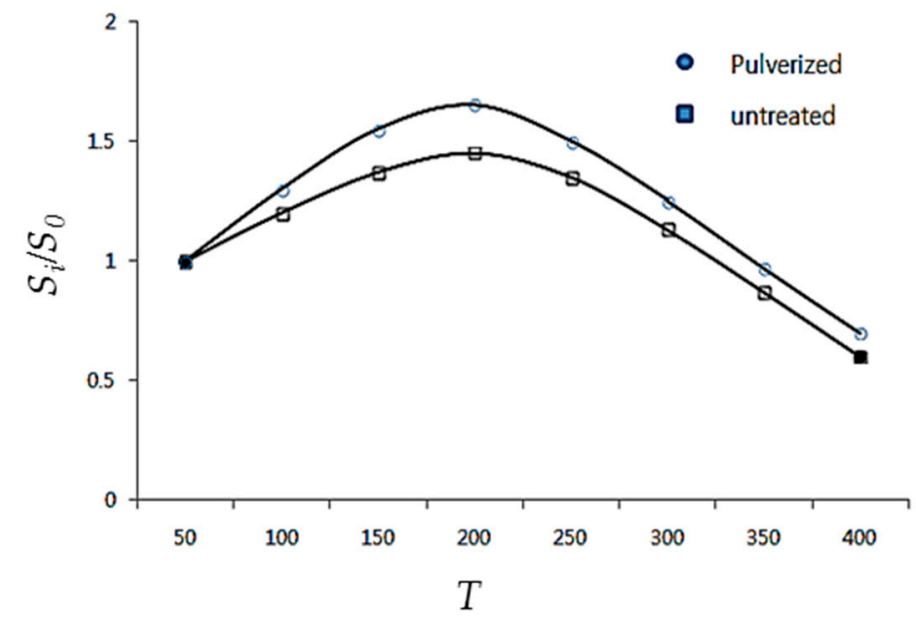

Figure 3. Relative specific surface area of heated $\mathrm{CaCO}_{3}$ compared to that of the untreated one.

Figure 3 shows a prominent increase in the specific surface area of the $\mathrm{CaCO}_{3}$ sample heat-treated up to $180^{\circ} \mathrm{C}$ followed by a drastic decrease in the specific surface area with further increases in the heat treatment temperature. The increase in the specific surface area of the heat-treated $\mathrm{CaCO}_{3}$ up to $180^{\circ} \mathrm{C}$ was attributed to the adsorption area being activated by the removal of foreign substances (primarily water) from the absorption area within the pores of the fine particles or powder surface, whereas the decrease in the specific surface area observed in the samples heat treated at temperatures above $180^{\circ} \mathrm{C}$ is believed to be the result of fine-sized sintering according to the surface expansion of unstable ions present on the powder surface [26]. This shows that, even over the temperature range well below the normal decomposition temperature of $900{ }^{\circ} \mathrm{C}$ for $\mathrm{CaCO}_{3}$, atoms on the activated surface area can rearrange themselves to change the adsorption properties of the surface. This can be observed even more distinctly in nanosized powders, where the nanosized $\mathrm{CaCO}_{3}$ generally has a large surface area to volume ratio and a larger percentage of surface-activated ions with unsaturated ionic bonds. Therefore, the functional properties such as adsorption, adhesion, and agglomeration are enhanced, whereas the handling and storage become increasingly difficult $[27,28]$. The active ratio was " 0 " in this study because the nontreated $\mathrm{CaCO}_{3}$ was precipitated in water. This study aims to modify $\mathrm{CaCO}_{3}$ to ascertain the possibility of its reusability in various industries. For this reason, we used fatty acids to modify $\mathrm{CaCO}_{3}$. General $\mathrm{CaCO}_{3}$ is hydrophilic and, thus, nontreated $\mathrm{CaCO}_{3}$ does not have resistance to water. Therefore, nontreated $\mathrm{CaCO}_{3}$ was precipitated in water, the result of which was different from that obtained with treated $\mathrm{CaCO}_{3}$. Fatty acids were used to change the $\mathrm{CaCO}_{3}$ properties. The fatty acids were dissolved in IPA (IsoPropyl Alcohol) and chloroform because they do not dissolve in water. IPA and chloroform have different end groups; thus, the solubility of each fatty acid was different. Each fatty acid was therefore selected by taking into account its chemical properties.

\subsection{Modification Effects of Calcite Using Fatty Acids as Modifier}

Among the fatty acid modifiers, stearic acid is the one most often used for nonpolarization of the $\mathrm{CaCO}_{3}$ powder surface because it contains a nonpolar long-chain $R$ group, which can facilitate nonpolar modification effects at the lowest decomposition melting temperature [29]. All results were compared to the duplicated results, and the difference was within $10 \%$. The results are supposed 
to relate to the interaction of stearic acid with minerals. However, this reaction mechanism was not clearly investigated.

Figures 4 and 5 (chloroform solvent) show changes in the active ratio according to the reaction time at each modifier solution concentration, which was modified by dissolving stearic acid in 2-propanol and chloroform solvent. 2-Propanol and chloroform solvent are well-known organic solvents. They were used to dissolve the fatty acids. In particular, the solubility of mineral particles in organic solvents was not considered because of its insignificance. Surface coverage and optimum treatment time were closely related to the dissolved stearic acid concentration and H-bonding status of the type of solvents used rather than the solubility.

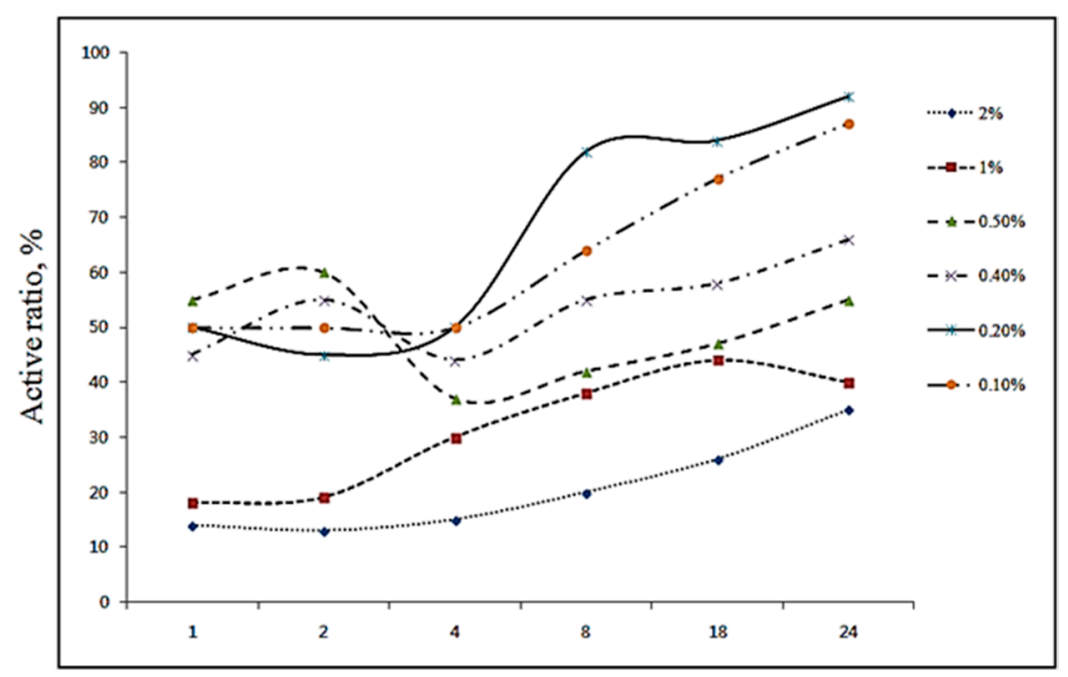

$\mathrm{h}$

Figure 4. Active ratio of modified $\mathrm{CaCO}_{3}$ powder with stearic acid in 2-propanol.

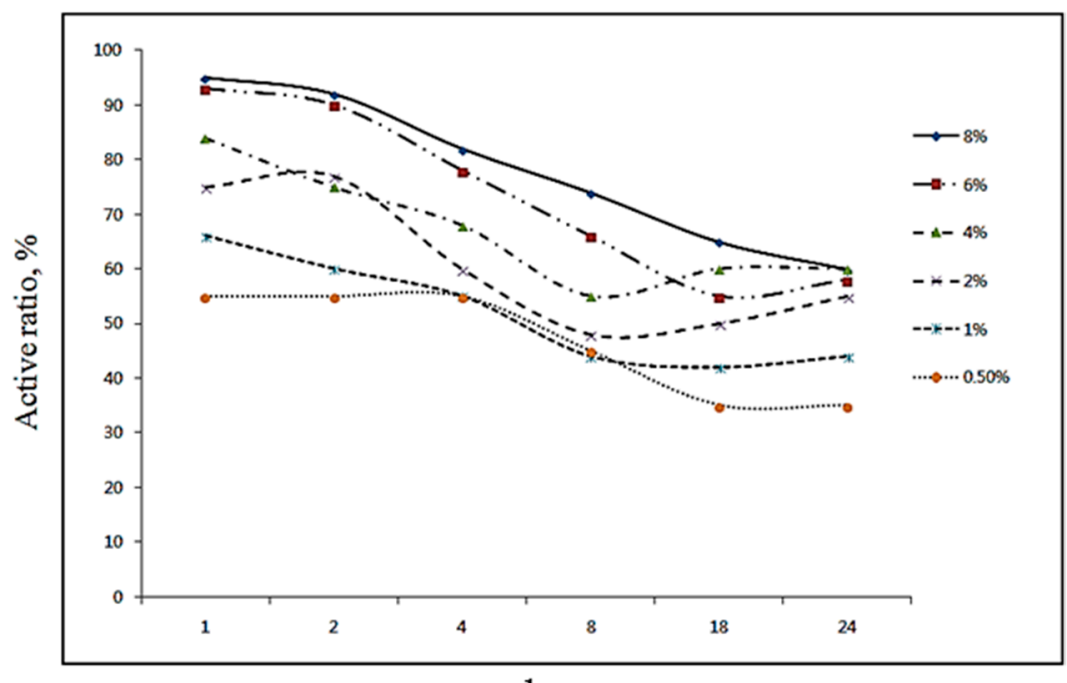

$\mathrm{h}$

Figure 5. Active ratio of modified $\mathrm{CaCO}_{3}$ powder with stearic acid in chloroform.

The reaction times in the 2-propanol solvent were 4, 8, 18, and $24 \mathrm{~h}$, whereas they were 1, 2, 4, and $8 \mathrm{~h}$ in chloroform, which shows that the adsorption equilibrium is achieved within a shorter time in chloroform than in 2-propanol. A closer examination of the results obtained using 2-propanol as the solvent, as shown in Figure 4, revealed an increase in the adsorption time with increasing 
active ratio. However, when chloroform was used as the solvent, as shown in Figure 5, the best active ratio was observed at a treatment of $1 \mathrm{~h}$, with the active ratio showing a distinct decrease with increasing treatment time. Therefore, the two solvents showed active ratio results based on the treatment time that were completely contradictory to each other. In general, 2-propanol shows an upward pattern and chloroform shows a decreasing trend with respect to the treatment time. Moreover, although 2-propanol showed the highest active ratio when it was treated at relatively dilute concentrations for a long time, chloroform showed the highest active ratio when it was treated at high concentrations for a short time. This was attributed to hydrogen bonding between the solvent and modifier because 2-propanol possesses an intramolecular hydroxyl group $(-\mathrm{OH})$, which allows the formation of a single hydrogen bond between the molecules, whereas stearic acid has structural characteristics that allow it to form double hydrogen bonds [7]. When the concentration of stearic acid in the 2-propanol solvent is very low, the hydrogen bonds between the stearic acid molecules are weak; this allows stearic acid with a relatively large dipole moment to be dominant in adsorption competition on the adsorption area of the $\mathrm{CaCO}_{3}$ surface, thereby showing high adsorption efficiency. It is also suspected that when the concentration of stearic acid increases, the formation of intermolecular double hydrogen bonds is promoted. This causes the terminal activation area to become nonpolar and have weak affinity to $\mathrm{CaCO}_{3}$, resulting in 2-propanol being polar-dominant to preoccupy the adsorption area of $\mathrm{CaCO}_{3}$. Consequently, a low concentration treated for a longer duration resulted in superior modification effects than the treatment at high concentrations. In contrast, in the nonpolar chloroform solvent, fatty acids have a much greater affinity to $\mathrm{CaCO}_{3}$ than to chloroform. Therefore, adsorption competition with the solvent is negligible, and a strong and rapid adsorption equilibrium can be expected in high concentrations of the modifier solution. Moreover, a decrease in the active ratio, which was observed when the treatment time was maintained for a long time, is believed to have originated from the stronger affinity between the nonpolar chloroform and nonpolar stearate than the binding force between the absorption group of stearate and the adsorption area on the $\mathrm{CaCO}_{3}$ powder surface. This caused the adsorption equilibrium between $\mathrm{CaCO}_{3}$-stearate-chloroform in the adsorption area of $\mathrm{CaCO}_{3}$ to shift toward the direction in which the fatty acids adsorbed on $\mathrm{CaCO}_{3}$ dissociate, leading to a lower active ratio.

Figure 6 presents the Fourier transform infrared (FT-IR) spectra of modified $\mathrm{CaCO}_{3}$ in 2-propanol solvent obtained based on changes in the treatment time and modifier concentration. In Figure 6, the modifier concentration and treatment time for modified $\mathrm{CaCO}_{3}$ spectra were assigned to the $-\mathrm{CH}_{2}$ and $-\mathrm{CH}_{3}$ stretching vibrations, which are indicators of the degree of modification. The intensity of these two peaks was highest where marked a) and lowest where marked d). Figure 7 presents the modified $\mathrm{CaCO}_{3}$ FT-IR spectra obtained when chloroform was used as the solvent; the modifier solution concentrations at the reaction times were larger and more distinct than those obtained for 2-propanol, as shown in Figure 6. Because the FTIR spectrum obtained at high concentrations and short reaction times (a) was dominant, the results were consistent with the active ratio shown earlier. To summarize the aforementioned active ratio and FT-IR results, the $-\mathrm{CH}_{2}$ and $-\mathrm{CH}_{3}$ absorption peaks observed in the chloroform solvent, which are dependent on the amount adsorbed, were much larger than those of 2-propanol. This suggests a larger amount of stearate adsorbed on the $\mathrm{CaCO}_{3}$ powder surface, whereas both solvents showed an excellent active ratio of $\geq 90 \%$ under their respective optimal conditions. The effective active ratio that took into account the unit adsorption amount was actually higher in 2-propanol. 


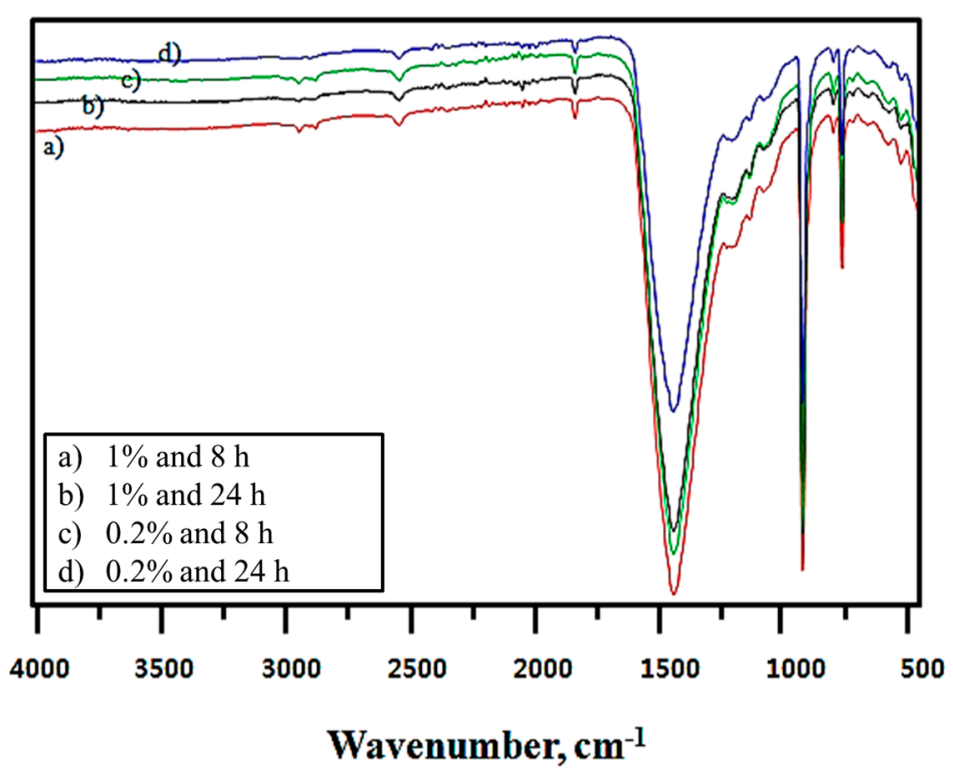

Figure 6. FT-IR spectra of modified $\mathrm{CaCO}_{3}$ in varied amounts of stearic acid and different aging times treated in the 2-propanol solvent.

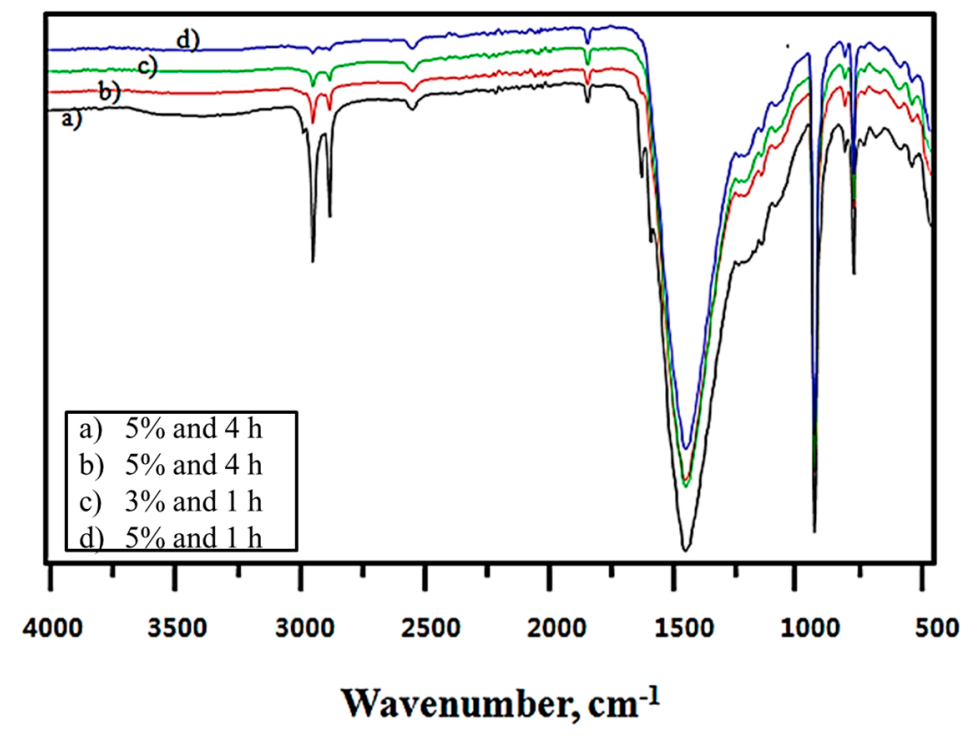

Figure 7. FT-IR spectra of modified $\mathrm{CaCO}_{3}$ in varied amounts of stearic acid and different aging times treated in the chloroform solvent.

Table 1 lists the modification effects of the $\mathrm{CaCO}_{3}$ surface modified using various fatty acids on the active and dispersing ratios. These results show the modification effects obtained under the optimal conditions for the concentration of fatty acid modifiers and treatment, which were obtained from the optimal solvent considering the solubility and dispersibility. From Table 1, we can see that the selected modifiers showed a better performance than the others. In particular, 2-propanol was better than chloroform in terms of saturated concentration because the saturated concentration of chloroform in each modifier was greater than that of 2-propanol by more than 35 times. Therefore, we presumed that 2-propanol has sufficient potential for application in industry from an economic viewpoint. According to Tran et al., fatty salt can improve surface modification when applied to PCC [3]. They used sodium series fatty acids to modify nano-PCC using a carbonation process. As a result, fatty acids improved 
the physicochemical properties and changed hydrophilic $\mathrm{CaCO}_{3}$ into hydrophobic $\mathrm{CaCO}_{3}$. Further details are provided in the next section.

Table 1. Effect of aliphatic modifiers coated with $\mathrm{CaCO}_{3}$ for optimum treatment.

\begin{tabular}{ccccccc}
\hline Modifier & Solvent & $\begin{array}{c}\text { Saturation } \\
\text { Concentration }(w / v)\end{array}$ & $\begin{array}{c}\text { Concentration } \\
\mathbf{( \% )}\end{array}$ & Time (h) & $\begin{array}{c}\text { Activation } \\
\text { Degree (\%) }\end{array}$ & $\begin{array}{c}\text { Dispersion } \\
\text { Ratio (\%) }\end{array}$ \\
\hline \multirow{2}{*}{ untreated } & - & - & - & - & 0 & 21 \\
\hline \multirow{2}{*}{ Stearic acid } & 2-Propanol & 0.25 & 0.2 & 24 & 94 & 64 \\
& Chloroform & 8.13 & 6.5 & 1 & 96 & 67 \\
\hline \multirow{2}{*}{ Palmitic acid } & 2-Propanol & 0.19 & 0.15 & 22 & 95 & 60 \\
& Chloroform & 6.87 & 5.5 & 1.2 & 94 & 62 \\
\hline \multirow{2}{*}{ Miristic acid } & 2-Propanol & 0.19 & 0.15 & 1.5 & 90 & 57 \\
& Chloroform & 6.25 & 5.0 & 20 & 92 & 60 \\
\hline \multirow{2}{*}{ Lauric acid } & 2-Propanol & 0.13 & 0.1 & 1.7 & 89 & 58 \\
& Chloroform & 5.87 & 4.7 & 20 & 91 & 61 \\
\hline \multirow{2}{*}{ Abietic acid } & Ethanol & 3.13 & 2.5 & 3 & 85 & 54 \\
\hline Oleic acid & Methanol & 5.24 & 4.2 & 4 & 88 & 65 \\
\hline
\end{tabular}

\subsection{Evaluation of the Contact Angle Characteristics}

The contact angle refers to the angle formed when liquid achieves thermodynamic equilibrium on a solid surface. This manifests in the wettability of a solid surface, with a larger contact angle corresponding to lower wettability, highly hydrophobic properties, and low surface energy value; a smaller contact angle corresponds to high hydrophilicity and relatively large surface energy [30]. The equation that expresses the relationship between the contact angle and interfacial energy is the Young's equation obtained under uniform, flat, and ideal surface conditions. This equation is used to obtain uniform values with high reproducibility in repeated measures [31]:

$$
\gamma_{L V \cos \theta}=\gamma_{S V}-\gamma_{S L}
$$

where $\gamma_{L V}$ denotes the liquid-gas interfacial tension; $\theta$ denotes the contact angle; $\gamma_{S V}$ denotes the solid-gas interfacial tension; and $\gamma_{S L}$ denotes the solid-liquid interfacial tension.

Figure 8 presents contact angles according to the surface coating rate of stearic acid. Unmodified $\mathrm{CaCO}_{3}$ showed complete wettability in all solvents because the surface energy of the powder, which comprised the spreading factor and polar factor, was very high [15]. The contact angle increased with increasing surface coating rate of stearic acid. According to published reports, when a fatty acid forms a complete single-molecule adsorption layer on $\mathrm{CaCO}_{3}$ powder, the maximum contact angles in water and formamide are approximately $103^{\circ}$ and $95^{\circ}$, respectively. This shows that the values almost reached the maximum value at a surface coating rate of $\geq 75 \%$ [32]. Although the fatty acid used had a high concentration, it did not exhibit any significant difference. According to Tran et al., the hydrophobic alkyl chain remains in the first layer of the $\mathrm{CaCO}_{3}$ coating of stearic acid [3]. Through this reaction, stearic acid was stored as a multilayer. Thus, a hydrophilic chain remained at the outer layer but most of it was removed by the dry process. Consequently, the modified $\mathrm{CaCO}_{3}$ exhibited hydrophilic characteristics. In this study, we also performed a similar process to modify $\mathrm{CaCO}_{3}$. Consequently, the results were in agreement with the results of other researchers. Therefore, even at a surface coating rate of approximately $75 \%$, a value similar to the surface energy in complete single-molecule adsorption was achieved and the results showed that fatty acids adsorbed on the powder surface were oriented vertically on the surface. 


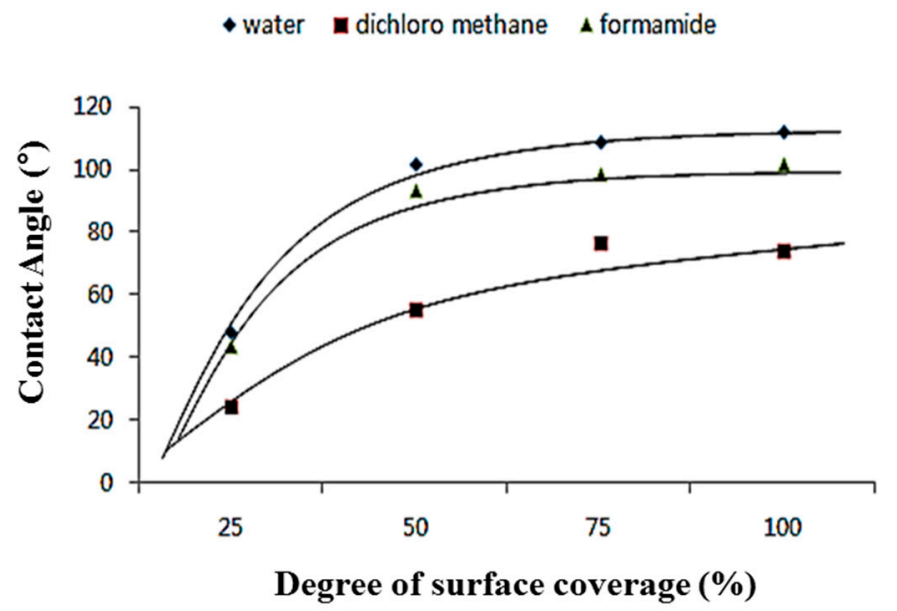

Figure 8. Contact angle of liquids, depending on the degree of coverage with stearic acid.

\section{Conclusions}

Surface characteristics of $\mathrm{CaCO}_{3}$ obtained from a mineral carbonation plant using desulfurized gypsum, an industrial byproduct, were modified to increase its usability as a filler for a range of industrial products such as paints, plastics, rubber, and paper. The chemical method involved modification using various types of fatty acids as modifiers, which were dissolved in organic solvents and admixed with $\mathrm{CaCO}_{3}$ to determine the optimal conditions according to various factors, such as the reaction speed, temperature, modifier concentration, and the specific solubility of the solvent. The effects on the hydrophobicity and dispersibility as well as changes in the physicochemical surface characteristics of the modified powder were investigated. All treatment processes were conducted at room temperature to eliminate the high thermal energy consumption required in conventional processes and the surface modification of $\mathrm{CaCO}_{3}$ was induced using a low-cost and high-efficiency method. The obtained modified $\mathrm{CaCO}_{3}$ powder showed a change in surface characteristics from a hydrophilic polar form with high surface energy to a hydrophobic nonpolar form with low surface energy, and exhibited high affinity and dispersibility when added as a filler in a polymer matrix. Therefore, we believe that this study will assist various industries in the field of $\mathrm{CaCO}_{3}$ usage.

In this study, we assumed that fatty acids have sufficient potential to modify $\mathrm{CaCO}_{3}$. However, this study used only two types of fatty acids, which means that other modification chemicals would need to be developed. Besides this, the practical application of modified $\mathrm{CaCO}_{3}$ is to be investigated. Since modified $\mathrm{CaCO}_{3}$ was coated with hydrophobic materials, we intend to use it in paper products and diapers to check its permeability and adhesion characteristics.

Acknowledgments: This research was supported by Basic Science Research Program through the National Research Foundation of Korea (NRF) funded by the Ministry of Science, ICT and Future Planning (NRF-2016R1C1B2013700), and by the Basic Research Project of the Korea Institute of Geoscience and Mineral Resources (KIGAM) funded by the Ministry of Science, ICT and future Planning.

Author Contributions: Chi wan Jeon suggested the idea for research and performed most of the experiments and analysis. And the other people operated pilot plant for producing $\mathrm{CaCO}_{3}$. Sangwon Park wrote this manuscript.

Conflicts of Interest: The authors declare no conflict of interest.

\section{References}

1. Park, S.; Bang, J.-H.; Song, K.; Jeon, C.W.; Park, J. Barium carbonate precipitation as a method to fix and utilize carbon dioxide. Chem. Eng. J. 2016, 284, 1251-1258. [CrossRef]

2. Touaiti, F.; Alam, P.; Toivakka, M.; Bousfield, D. Polymer chain pinning at interfaces in $\mathrm{CaCO}_{3}-\mathrm{SBR}_{\text {latex }}$ composites. Mater. Sci. Eng. A 2010, 527, 2363-2369. [CrossRef] 
3. Tran, H.V.; Dai Tran, L.; Vu, H.D.; Thai, H. Facile surface modification of nanoprecipitated calcium carbonate by adsorption of sodium stearate in aqueous solution. Colloids Surf. A Physicochem. Eng. Asp. 2010, 366, 95-103. [CrossRef]

4. Gao, X.; Zhu, Y.; Zhou, S.; Gao, W.; Wang, Z.; Zhou, B. Preparation and characterization of well-dispersed waterborne polyurethane $/ \mathrm{CaCO}_{3}$ nanocomposites. Colloids Surf. A Physicochem. Eng. Asp. 2011, 377, 312-317. [CrossRef]

5. He, H.; Li, K.; Wang, J.; Sun, G.; Li, Y.; Wang, J. Study on thermal and mechanical properties of nano-calcium carbonate/epoxy composites. Mater. Des. 2011, 32, 4521-4527. [CrossRef]

6. Cao, Z.; Daly, M.; Clémence, L.; Geever, L.M.; Major, I.; Higginbotham, C.L.; Devine, D.M. Chemical surface modification of calcium carbonate particles with stearic acid using different treating methods. Appl. Surf. Sci. 2016, 378, 320-329. [CrossRef]

7. Osman, M.A.; Suter, U.W. Surface treatment of calcite with fatty acids: Structure and properties of the organic monolayer. Chem. Mater. 2002, 14, 4408-4415. [CrossRef]

8. Ma, C.; Rong, M.; Zhang, M. Influence of nano- $\mathrm{CaCO}_{3}$ and surface modification on the crystallization behavior of isotactic polypropylene. Acta Polym. Sin. 2003, 3, 381-386.

9. Hu, L.; Yuan, J.; Wang, C. The present research situation and the prospects of mineral fibers used in papermaking. China Non-Metall. Min. Ind. Her. 2006, 4. [CrossRef]

10. El-Sherbiny, S.; El-Sheikh, S.M.; Barhoum, A. Preparation and modification of nano calcium carbonate filler from waste marble dust and commercial limestone for papermaking wet end application. Powder Technol. 2015, 279, 290-300. [CrossRef]

11. Song, E.; Kim, D.; Kim, B.J.; Lim, J. Surface modification of $\mathrm{CaCO}_{3}$ nanoparticles by alkylbenzene sulfonic acid surfactant. Colloids Surf. A Physicochem. Eng. Asp. 2014, 461, 1-10. [CrossRef]

12. Rungruang, P.; Grady, B.P.; Supaphol, P. Surface-modified calcium carbonate particles by admicellar polymerization to be used as filler for isotactic polypropylene. Colloids Surf. A Physicochem. Eng. Asp. 2006, 275, 114-125. [CrossRef]

13. Liang, J. Evaluation of dispersion of nano- $\mathrm{CaCO}_{3}$ particles in polypropylene matrix based on fractal method. Compos. Part A Appl. Sci. Manuf. 2007, 38, 1502-1506. [CrossRef]

14. Wang, Q.; Zhang, X.; Dong, W.; Gui, H.; Gao, J.; Lai, J.; Liu, Y.; Huang, F.; Song, Z.; Qiao, J. Novel rigid poly (vinyl chloride) ternary nanocomposites containing ultrafine full-vulcanized powdered rubber and untreated nano-sized calcium carbonate. Mater. Lett. 2007, 61, 1174-1177. [CrossRef]

15. Sarkar, A.; Ghosh, A.K.; Mahapatra, S. Lauric acid triggered in situ surface modification and phase selectivity of calcium carbonate: Its application as an oil sorbent. J. Mater. Chem. 2012, 22, 11113. [CrossRef]

16. Jiang, J.; Liu, J.; Liu, C.; Zhang, G.; Gong, X.; Liu, J. Roles of oleic acid during micropore dispersing preparation of nano-calcium carbonate particles. Appl. Surf. Sci. 2011, 257, 7047-7053. [CrossRef]

17. Tester, C.C.; Brock, R.E.; Wu, C.-H.; Krejci, M.R.; Weigand, S.; Joester, D. In vitro synthesis and stabilization of amorphous calcium carbonate (ACC) nanoparticles within liposomes. CrystEngComm 2011, 13, 3975. [CrossRef]

18. Yu, P.T.; Tsao, C.; Wang, C.C.; Chang, C.Y.; Wang, C.H.; Chan, J.C.C. High-magnesium calcite mesocrystals: Formation in aqueous solution under ambient conditions. Angew. Chem. Int. Ed. Engl. 2017, 56, 16202-16206. [CrossRef] [PubMed]

19. Pérez-Moreno, S.M.; Gázquez, M.J.; Bolívar, J.P. $\mathrm{CO}_{2}$ sequestration by indirect carbonation of artificial gypsum generated in the manufacture of titanium dioxide pigments. Chem. Eng. J. 2015, 262, 737-746. [CrossRef]

20. Azdarpour, A.; Asadullah, M.; Mohammadian, E.; Junin, R.; Hamidi, H.; Manan, M.; Daud, A.R.M. Mineral carbonation of red gypsum via ph-swing process: Effect of $\mathrm{CO}_{2}$ pressure on the efficiency and products characteristics. Chem. Eng. J. 2015, 264, 425-436. [CrossRef]

21. Morales-Flórez, V.; Santos, A.; Lemus, A.; Esquivias, L. Artificial weathering pools of calcium-rich industrial waste for $\mathrm{CO}_{2}$ sequestration. Chem. Eng. J. 2011, 166, 132-137. [CrossRef]

22. Carre, A.; Schultz, J. Polymer-aluminium adhesion. I. The surface energy of aluminium in relation to its surface treatment. J. Adhes. 1983, 15, 151-161. [CrossRef]

23. Kessaissia, Z.; Papirer, E.; Donnet, J.-B. Molecular transitions of alkyl chains grafted onto silicas, observed by gas chromatography. J. Colloid Interface Sci. 1981, 79, 257-263. [CrossRef] 
24. Bang, J.-H.; Jang, Y.N.; Kim, W.; Song, K.S.; Jeon, C.W.; Chae, S.C.; Lee, S.-W.; Park, S.-J.; Lee, M.G. Specific surface area and particle size of calcium carbonate precipitated by carbon dioxide microbubbles. Chem. Eng. J. 2012, 198-199, 254-260. [CrossRef]

25. Kristof, E.; Juhasz, A. The effect of intensive grinding on the crystal structure of dolomite. Powder Technol. 1993, 75, 145-152. [CrossRef]

26. Gao, W.; Ma, X.; Wang, Z.; Zhu, Y. The influence of surface modification on the structure and properties of a calcium carbonate filled poly(ethylene terephthalate). Colloids Surf. A Physicochem. Eng. Asp. 2011, 389, 230-236. [CrossRef]

27. Ghatee, M.H.; Koleini, M.M.; Ayatollahi, S. Molecular dynamics simulation investigation of hexanoic acid adsorption onto calcite surface. Fluid Ph. Equilib. 2015, 387, 24-31. [CrossRef]

28. Gao, Z.; Bai, D.; Sun, W.; Cao, X.; Hu, Y. Selective flotation of scheelite from calcite and fluorite using a collector mixture. Miner. Eng. 2015, 72, 23-26. [CrossRef]

29. Ricci, M.; Segura, J.J.; Erickson, B.W.; Fantner, G.; Stellacci, F.; Voitchovsky, K. Growth and dissolution of calcite in the presence of adsorbed stearic acid. Langmuir 2015, 31, 7563-7571. [CrossRef] [PubMed]

30. Santos, E.P.; Dutra, A.J.B.; Oliveira, J.F. The effect of jojoba oil on the surface properties of calcite and apatite aiming at their selective flotation. Int. J. Miner. Process. 2015, 143, 34-38. [CrossRef]

31. Adams, E.; Uhlig, K.; Tang, Y.-H.; Haas, G. Solidification and superfluidity of ${ }^{4} \mathrm{He}$ in confined geometries. Phys. Rev. Lett. 1984, 52, 2249. [CrossRef]

32. Elaine, G.S.; William, A.Z. Upper limits to the contact angles of liquids on solids. In Contact Angle, Wettability, and Adhesion; American Chemical Society: Washington, DC, USA, 1964; Volume 43, pp. 145-157.

(C) 2018 by the authors. Licensee MDPI, Basel, Switzerland. This article is an open access article distributed under the terms and conditions of the Creative Commons Attribution (CC BY) license (http:/ / creativecommons.org/licenses/by/4.0/). 